\title{
Preparation of $\mathrm{SO}_{4}^{2-} / \mathrm{TiO}_{2}-\mathrm{La}_{2} \mathrm{O}_{3}$ solid superacid and its catalytic activities in acetalation and ketalation*
}

\author{
YANG Shui-jin $^{\dagger 1}$, BAI Ai-min ${ }^{1}$, SUN Ju-tang ${ }^{2}$ \\ ( ${ }^{1}$ Department of Chemistry and Environmental Engineering, Hubei Normal University, Huangshi 435002, China) \\ $\left({ }^{2}\right.$ College of Chemistry and Molecular Sciences, Wuhan University, Wuhan 430072, China) \\ 'E-mail: yangshuijin@163.com \\ Received Nov. 16, 2005; revision accepted Apr. 17, 2006
}

\begin{abstract}
SO}_{4}^{2-} / \mathrm{TiO}_{2}-\mathrm{La}_{2} \mathrm{O}_{3}$, a novel solid superacid, was prepared and its catalytic activities at different synthetic conditions are discussed with esterification of $n$-butanoic acid and $n$-butyl alcohol as probing reaction. The optimum conditions have also been found, mole ratio of $n\left(\mathrm{La}^{3+}\right): n\left(\mathrm{Ti}^{4+}\right)$ is $1: 34$, the soaked consistency of $\mathrm{H}_{2} \mathrm{SO}_{4}$ is $0.8 \mathrm{~mol} / \mathrm{L}$, the soaked time of $\mathrm{H}_{2} \mathrm{SO}_{4}$ is $24 \mathrm{~h}$, the calcining temperature is $480^{\circ} \mathrm{C}$, the calcining time is $3 \mathrm{~h}$. Then it was applied in the catalytic synthesis of ten important ketals and acetals as catalyst and revealed high catalytic activity. Under these conditions on which the molar ratio of aldehyde/ketone to glycol is $1: 1.5$, the mass ratio of the catalyst used in the reactants is $0.5 \%$, and the reaction time is $1.0 \mathrm{~h}$, the yields of ketals and acetals can reach $41.4 \% \sim 95.8 \%$.
\end{abstract}

Key words: $\mathrm{SO}_{4}^{2-} / \mathrm{TiO}_{2}-\mathrm{La}_{2} \mathrm{O}_{3}$, Rare earth, Solid superacid, Catalysis

doi:10.1631/jzus.2006.B0553 Document code: A CLC number: TQ655

\section{INTRODUCTION}

There is considerable interest in synthesizing acetals and ketals as important perfume substances and industrial raw materials of organic synthesis (Loader and Anderson, 1978; Dhrubojyoti et al., 1999; Wang et al., 1992b). Concentrated sulfuric acid and other analogous Brönsted acids used as catalysts in industrial processes for many years, exposed their defects, such as the corrosion of the reactors, difficulties in product separation and catalyst recovery, pollution by acidic waste water, poor quality of the products, etc. The alternative catalysts, for example, transition metal salt (Dhrubojyoti et al., 1999; Li and Cheng, 2001), $\mathrm{TiSiW}_{12} \mathrm{O}_{40} / \mathrm{TiO}_{2}$ (Yang et al., 2003), tungstosilicic acid supported on active carbon (Yang

\footnotetext{
* Project supported by the National Natural Science Foundation of China (No. 20471044), and the Natural Science Foundation of Hubei Province (No. 2005ABA053), China
}

et al., 2005a), montmorillonite K 10 (Li et al., 1996), solid superacid (Wang et al., 1992b), have been developed for environmental protection and technoeconomical profit. Among substitutes, much attention has been paid to solid superacids in various industrial processes due to their successful application in several important acid-catalyzed reactions (esterification, acelation) (Wang et al., 1992b; Kirbaslar et al., 2001; Hess and Kemnitz, 1997). Lu and Zu (2002) reported that the $\mathrm{SO}_{4}^{2-}-\mathrm{M}_{x} \mathrm{O}_{y}$-type solid superacid has excellent catalytic activity for esterification due to its super acidity in heterogeneous systems. However, the structural stability and the catalytic activity should be further improved. It was suggested that intermingling $\mathrm{SO}_{4}^{2-}-\mathrm{M}_{x} \mathrm{O}_{y}$ with transition metal oxides was a possible method for solving the above problems (Ma and Li, 2002; Yang et al., 2005b). We found it had better catalytic activity when $\mathrm{La}_{2} \mathrm{O}_{3}$ was selected.

In this paper, we report the compositing method 
for a new kind of solid superacid- $\mathrm{SO}_{4}^{2-} / \mathrm{TiO}_{2}-\mathrm{La}_{2} \mathrm{O}_{3}$ and discuss its catalytic activity under different synthetic conditions, esterification of $n$-butanoic acid and $n$-butyl alcohol as probing reaction. Solid superacid- $\mathrm{SO}_{4}^{2-} / \mathrm{TiO}_{2}-\mathrm{La}_{2} \mathrm{O}_{3}$ was used as catalyst to synthesize acetals and ketals for the first time and the corresponding catalytic activity was investigated.

\section{EXPERIMENTAL DETAILS}

\section{Materials and measurements}

All chemicals were commercial products of reagent grade. The X-ray powder diffraction pattern of the powder samples was measured by a Rigaku model XRD-6000 X-ray diffractometer employing $\mathrm{Cu} K_{\alpha}$ radiation with the accelerating voltage $40 \mathrm{kV}$ and applied current of $30 \mathrm{~mA}$, respectively in scanning range of $2 \theta$ of $10^{\circ} \sim 70^{\circ}$. The infrared spectra were recorded on a Nicolet 5DX FT-IR spectrophotometer with liquid membrane in the $400 \sim 4000 \mathrm{~cm}^{-1}$ region. ${ }^{1} \mathrm{H}$ NMR spectra were determined on a MERCURY-VX $300 \mathrm{MHz}$ spectrometer with tetramethylsilane (TMS) as internal standard in $\mathrm{CDCl}_{3}$. The $\mathrm{SO}_{4}^{2-}$ and $\mathrm{La}_{2} \mathrm{O}_{3}$ content in the $\mathrm{SO}_{4}^{2-} /$ $\mathrm{TiO}_{2}-\mathrm{La}_{2} \mathrm{O}_{3}$ were determined by chemical analysis.

\section{Preparation of $\mathrm{SO}_{4}^{2-} / \mathrm{TiO}_{2}-\mathrm{La}_{2} \mathrm{O}_{3}$}

$\mathrm{SO}_{4}^{2-} / \mathrm{TiO}_{2}-\mathrm{La}_{2} \mathrm{O}_{3}$ was prepared as follows. Hydroxides or oxides of $\mathrm{Ti}$ and $\mathrm{La}$ were obtained by dissolving chloride of $\mathrm{Ti}$ and $\mathrm{La}$ in water, hydrolyzing with aqueous ammonia to $\mathrm{pH}=8 \sim 9$ in solution, washing the precipitate, drying at $110{ }^{\circ} \mathrm{C}$, and powdering it. The precipitates were treated with sulfate ion by immersing the dried Ti-La-O substrate in 0.8 $\mathrm{mol} / \mathrm{L} \mathrm{H}_{2} \mathrm{SO}_{4}$ solution for $24 \mathrm{~h}$, then filtered, dried, and calcinated in furnace at $480{ }^{\circ} \mathrm{C}$ for $3 \mathrm{~h}$. Finally the catalysts were stored in a desiccator until use. The microstructure of $\mathrm{SO}_{4}^{2-} / \mathrm{TiO}_{2}-\mathrm{La}_{2} \mathrm{O}_{3}$ was identified by means of FT-IR and XRD.

\section{Determination of sulphate content}

Sulphate-modified $\mathrm{TiO}_{2}-\mathrm{La}_{2} \mathrm{O}_{3}$ samples calcined at different temperatures were fused by $m(\mathrm{ZnO})$ : $m\left(\mathrm{Na}_{2} \mathrm{CO}_{3}\right)=4: 1$, and extracted with water. The filtrate was titrated for sulphate estimation by the stan- dard procedure (Gao et al., 1994).

\section{Acid strength measurement of catalysts}

The acid strengths of the catalysts were examined by the colour change method using the Hammett indicator (Gao et al., 1992), when a powdered sample was added to an indicator dissolved in dry benzene.

\section{Synthesis of acetals and ketals}

The reaction was carried out in a three-neck flask equipped with a stirrer, a reflux condenser and a thermometer. Certain amounts of ethyl acetoacetate, cyclohexanone, butanone, butyraldehyde, benzaldehyde were added separately with alcohol (ethylene glycol or 1,2-propylene glycol) and the catalyst. The solution was heated to boiling and refluxed until no water flowed off, then distilled after ridding the water anhydrous magnesium sulfate to obtain the desired product.

\section{RESULTS AND DISCUSSION}

\section{Solid-state structure of the complexes}

1. Infrared spectra of $\mathrm{SO}_{4}^{2-} / \mathrm{TiO}_{2}-\mathrm{La}_{2} \mathrm{O}_{3}$

Fig.1 shows the IR spectra of $\mathrm{SO}_{4}^{2-} / \mathrm{TiO}_{2}-\mathrm{La}_{2} \mathrm{O}_{3}$. Infrared spectrum of solid samples (Fig.1) showed that the characteristic peaks of $\mathrm{SO}_{4}^{2-} / \mathrm{TiO}_{2}-\mathrm{La}_{2} \mathrm{O}_{3}$ are at $1379 \mathrm{~cm}^{-1}, 1132 \mathrm{~cm}^{-1}$ and $1043 \mathrm{~cm}^{-1}$, indicating sulphurous species on the catalyst surface (Gao et al., 1996) and provide the corner of strong acid by induction, with the result according with reports of $\mathrm{SO}_{4}^{2-}-\mathrm{M}_{x} \mathrm{O}_{y}$-type solid superacid in (Yin et al., 1994).

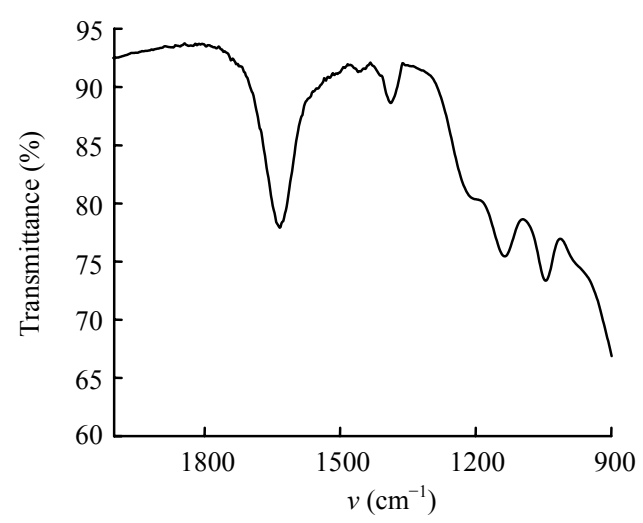

Fig.1 IR spectra of $\mathrm{SO}_{4}^{2-} / \mathrm{TiO}_{2}-\mathrm{La}_{2} \mathrm{O}_{3}$ 
Generally, there are two absorption bands in the infrared spectrum of $\mathrm{SO}_{4}^{2-}-\mathrm{M}_{x} \mathrm{O}_{y}$-type solid super acid at $900 \sim 1300 \mathrm{~cm}^{-1}$ and $1300 \sim 1400 \mathrm{~cm}^{-1}$, which can be attributable to the vibration of $\mathrm{S}=\mathrm{O}$ being similar to that of sulfate and sulfuric ester, respectively. The absorption peaks at low frequency partly show double bond in the former and fully show double bond at high frequency in the latter. And we can surmise that adsorbed water exists in the catalyst compound as shown by the strong and broad peaks at $1636 \mathrm{~cm}^{-1}$ and $3415 \mathrm{~cm}^{-1}$ attributable to the bending vibrations of $\mathrm{H}-\mathrm{O}-\mathrm{H}$ bond and the stretching vibrations of $\mathrm{O}-\mathrm{H}$. The peak at $1383 \mathrm{~cm}^{-1}$ is distinguished from the $1630 \sim 1620 \mathrm{~cm}^{-1}$ sulphate pears for the double coordination between metal ions and $\mathrm{SO}_{4}^{2-}$.

\section{X-ray structure of $\mathrm{SO}_{4}^{2-} / \mathrm{TiO}_{2}-\mathrm{La}_{2} \mathrm{O}_{3}$}

The X-ray powder diffraction spectrum of solid samples (Fig.2) suggests anatase crystalline phase in both $\mathrm{SO}_{4}^{2-} / \mathrm{TiO}_{2}$ and $\mathrm{SO}_{4}^{2-} / \mathrm{TiO}_{2}-\mathrm{La}_{2} \mathrm{O}_{3}$ having the same value of diffraction peaks. We did not find the diffraction peaks that $\mathrm{La}_{2} \mathrm{O}_{3}$ should display, indicating that no sole crystalline phase caused by $\mathrm{La}_{2} \mathrm{O}_{3}$ and $\mathrm{La}$ is dispersed on the catalyst surface in case the amount of $\mathrm{La}$ is below a threshold value (Pan and Xie, 2001). The mass fraction of $\mathrm{SO}_{4}^{2-}$ and $\mathrm{La}_{2} \mathrm{O}_{3}$ in the $\mathrm{SO}_{4}^{2-} / \mathrm{TiO}_{2}-\mathrm{La}_{2} \mathrm{O}_{3}$ are about $9.48 \%$ and $0.70 \%$, respectively.

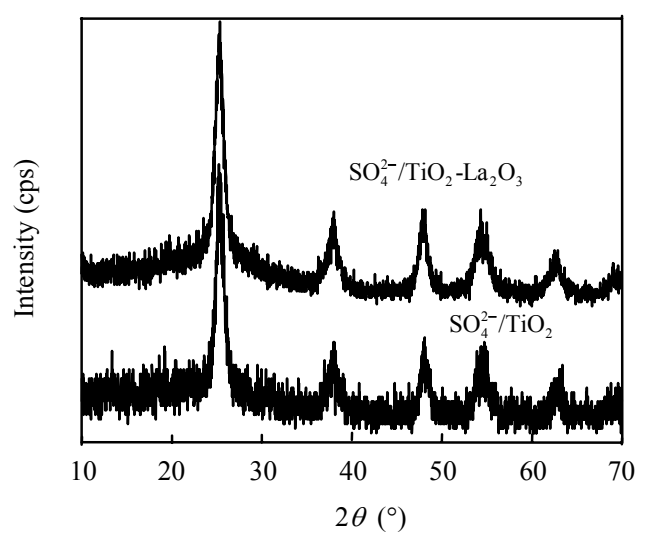

Fig.2 X-ray powder diffraction spectra of $\mathrm{SO}_{4}^{2-} / \mathrm{TiO}_{2}-\mathrm{La}_{2} \mathrm{O}_{3}$ and $\mathrm{SO}_{4}^{2-} / \mathrm{TiO}_{2}$

\section{Acid strengths of the catalysts}

The acid strengths of the catalysts were examined by the colour change method using the Hammett indicator (2,4-dinitroluene $\left(H_{0}=-14.52\right), 1,3,5$-trini- trotoluene $\left.\left(H_{0}=-16.04\right)\right)$. It was seen that the Hammett acidity function of $\mathrm{SO}_{4}^{2-} / \mathrm{TiO}_{2}-\mathrm{La}_{2} \mathrm{O}_{3}$ is $-16.04<H_{0}<-14.52$.

\section{Effect of preparation conditions on the activity of $\mathrm{SO}_{4}^{2-} / \mathrm{TiO}_{2}-\mathrm{La}_{2} \mathrm{O}_{3}$ catalysts}

The reaction was carried out in a three-neck flask equipped with a stirrer, a reflux condenser and a thermometer. Certain amounts of $n$-butanoic acid and $n$-butyl alcohol were added with molar ratio of acid to alcohol being 1.3:1 separately, mass ratio of the catalyst used in the reactants being $1.5 \%$. The solution was heated to boiling in the range of $94{ }^{\circ} \mathrm{C}$ to $112{ }^{\circ} \mathrm{C}$ and refluxed for $1 \mathrm{~h}$. To find the optimum reaction factors affecting activities of $\mathrm{SO}_{4}^{2-} / \mathrm{TiO}_{2}-\mathrm{La}_{2} \mathrm{O}_{3}$, we studied the effects of mole ratio of $n\left(\mathrm{La}^{3+}\right): n\left(\mathrm{Ti}^{4+}\right)$ included in compound, soaked consistency of $\mathrm{H}_{2} \mathrm{SO}_{4}$, impregnation time of $\mathrm{H}_{2} \mathrm{SO}_{4}$, calcination temperature and burnt time on the results shown in Fig.3.

The preparation conditions are important factors affecting the $\mathrm{SO}_{4}^{2-} / \mathrm{TiO}_{2}-\mathrm{La}_{2} \mathrm{O}_{3}$ properties. The results in Fig.3a show influences of the mole ratio of $n\left(\mathrm{La}^{3+}\right): n\left(\mathrm{Ti}^{4+}\right)$ on the catalytic activity of $\mathrm{SO}_{4}^{2-} /$ $\mathrm{TiO}_{2}-\mathrm{La}_{2} \mathrm{O}_{3}$ prepared under the following conditions: impregnation time in $0.8 \mathrm{~mol} / \mathrm{L} \mathrm{H}_{2} \mathrm{SO}_{4}, 24 \mathrm{~h}$; calcinations temperature of $\mathrm{SO}_{4}^{2-} / \mathrm{TiO}_{2}-\mathrm{La}_{2} \mathrm{O}_{3}, 480{ }^{\circ} \mathrm{C}$; burnt time, $3 \mathrm{~h}$. The results showed that the $\mathrm{SO}_{4}^{2-} /$ $\mathrm{TiO}_{2}-\mathrm{La}_{2} \mathrm{O}_{3}$ catalytic activity under mole ratio of $n\left(\mathrm{La}^{3+}\right): n\left(\mathrm{Ti}^{4+}\right)=1: 34$ is relatively higher.

The results in Fig.3b and Fig.3c show the influences of the $\mathrm{H}_{2} \mathrm{SO}_{4}$ solution concentration used and the impregnation time on the $\mathrm{SO}_{4}^{2-} / \mathrm{TiO}_{2}-\mathrm{La}_{2} \mathrm{O}_{3}$ activities, showing that immersion of $\mathrm{TiO}_{2}-\mathrm{La}_{2} \mathrm{O}_{3}$ in 0.8 $\mathrm{mol} / \mathrm{L} \mathrm{H}_{2} \mathrm{SO}_{4}$ for $24 \mathrm{~h}$ is appropriate for the preparation of $\mathrm{SO}_{4}^{2-} / \mathrm{TiO}_{2}-\mathrm{La}_{2} \mathrm{O}_{3}$ catalyst, which show higher esterification activity, indicating that a proper amount of $\mathrm{SO}_{4}^{2-}$ on $\mathrm{TiO}_{2}-\mathrm{La}_{2} \mathrm{O}_{3}$ is necessary to achieve high activity. If the $\mathrm{SO}_{4}^{2-}$ amount added to the catalyst surface is more or less than the proper amount, high $\mathrm{SO}_{4}^{2-} / \mathrm{TiO}_{2}-\mathrm{La}_{2} \mathrm{O}_{3}$ activity cannot be achieved.

The results in Fig.3d and Fig.3e show influences of calcination temperature and the burnt time on the $\mathrm{SO}_{4}^{2-} / \mathrm{TiO}_{2}-\mathrm{La}_{2} \mathrm{O}_{3}$ activities. It is known that the calcination temperature in the preparation of a cata- 
lyst and the burnt time are key factors, which not only can affect the $\mathrm{SO}_{4}^{2-}$ amount added to the catalyst surface but the activity of the catalysts as well. The results showed that the catalytic activity of $\mathrm{SO}_{4}^{2-} / \mathrm{TiO}_{2}-\mathrm{La}_{2} \mathrm{O}_{3}$ calcined at about $480{ }^{\circ} \mathrm{C}$ for $3 \mathrm{~h}$ is higher than that calcined at other temperatures, and that above $480^{\circ} \mathrm{C}$ this sulphureous complex gradually decomposes.

We changed only one of the five reaction factors and kept the others constant in the experimental runs, then the optimum conditions were selected. That is, the mole ratio of $n\left(\mathrm{La}^{3+}\right): n\left(\mathrm{Ti}^{4+}\right)$ is $1: 34$, the soaked consistency of $\mathrm{H}_{2} \mathrm{SO}_{4}$ is $0.8 \mathrm{~mol} / \mathrm{L}$, impregnation time of $\mathrm{H}_{2} \mathrm{SO}_{4}$ is $24 \mathrm{~h}$, the calcination temperature is 480 ${ }^{\circ} \mathrm{C}$, the burnt time is $3 \mathrm{~h}$.

\section{Comparsion of catalytic activity of different cata- lysts}

Table 1 summarizes the activities of $\mathrm{SO}_{4}^{2-} / \mathrm{TiO}_{2}-$ $\mathrm{La}_{2} \mathrm{O}_{3}$ and $\mathrm{H}_{2} \mathrm{SO}_{4}, \mathrm{H}_{3} \mathrm{PW}_{12} \mathrm{O}_{40}$ (Zhang et al., 1993) for

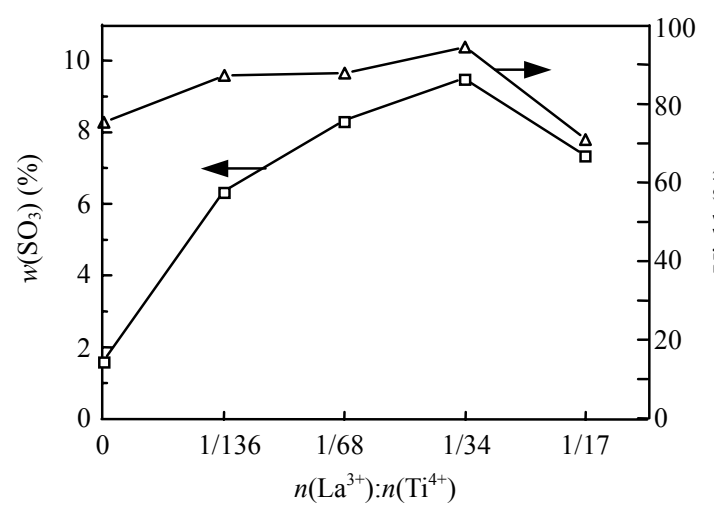

(a)

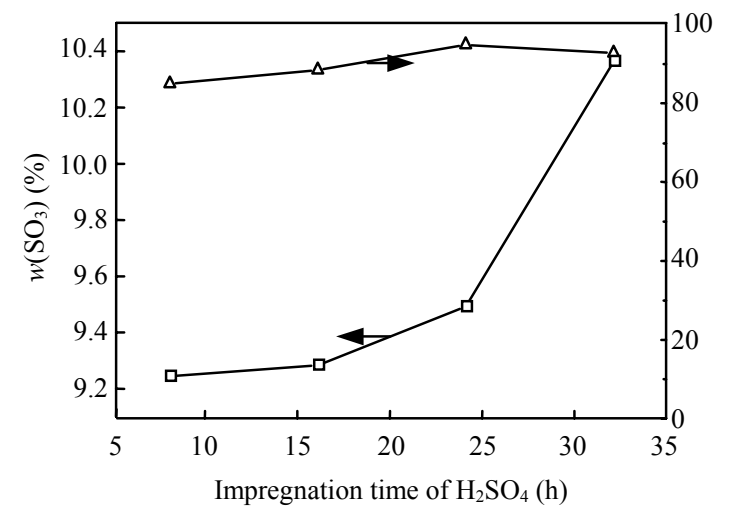

(c)

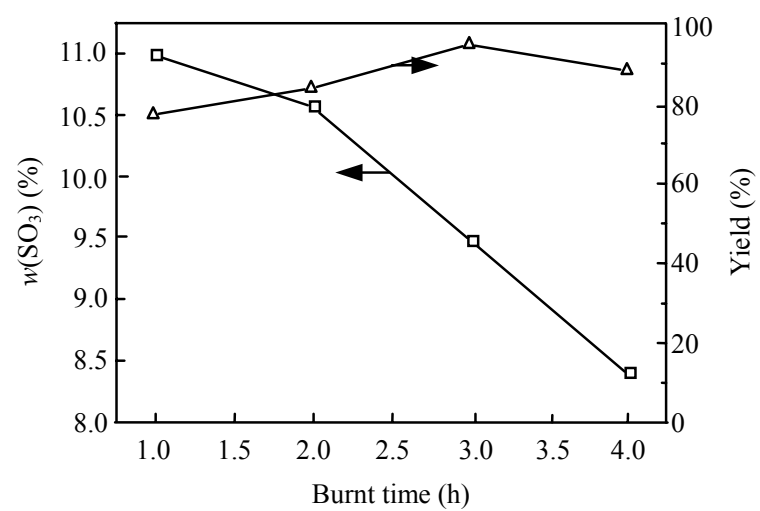

(e)

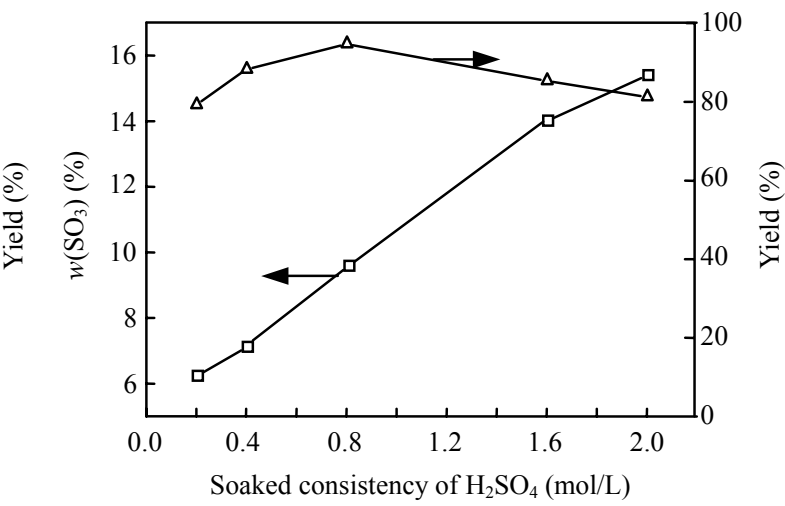

(b)

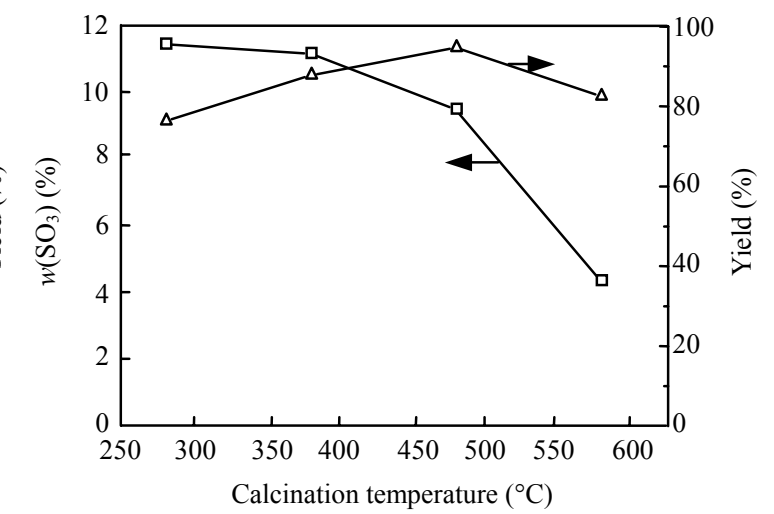

(d)

Fig.3 Effects of (a) mole ratio of $n\left(\mathrm{La}^{3+}\right): n\left(\mathrm{Ti}^{4+}\right)$, (b) soaked consistency of $\mathrm{H}_{2} \mathrm{SO}_{4}$, (c) impregnation time of $\mathrm{H}_{2} \mathrm{SO}_{4}$, (d) calcination temperature and (e) burnt time on catalytic activity 
esterification of $n$-butanoic acid and $n$-butyl alcohol. The activity of catalysts and other data were obtained at the temperature of the reactant solution reflux.

$\mathrm{SO}_{4}^{2-} / \mathrm{TiO}_{2}-\mathrm{La}_{2} \mathrm{O}_{3}$ has the most intense catalytic activity among these $\mathrm{H}_{2} \mathrm{SO}_{4}$ and $\mathrm{H}_{3} \mathrm{PW}_{12} \mathrm{O}_{40}$ acid catalysts, even if compared on the basis of the catalyst weight and reaction time.

\section{Acetals and ketals}

Some equations and experiment results on the synthetic acetals and ketals are listed:

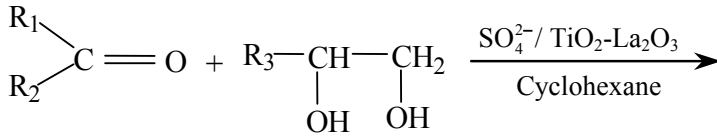

$$
\begin{aligned}
& 1 \\
& 2 \\
& { }_{\mathrm{R}_{2}}^{\mathrm{R}_{1}} \succ \mathrm{C}>{ }_{\mathrm{O}-\mathrm{CH}_{2}}^{\mathrm{O}-\mathrm{R}_{3}}+\mathrm{H}_{2} \mathrm{O} \\
& \mathbf{3 a} \sim \mathbf{3 j}
\end{aligned}
$$

The yield of ten classes of acetals and ketals under typical reaction conditions (molar ratio of aldehyde/ketone to glycol is $1: 1.5$, the quantity of catalyst is equal to $0.5 \%$ of feed stocks, the reaction time is $1.0 \mathrm{~h}$ ) can reach $41.4 \% \sim 95.8 \%$. The amount of reactant of aldehyde/ketone was fixed in 0.2 mol with cyclohexane as water-removed reagent. Results of these synthesis reactions are summarized in Table 2.

From the data listed in the table, we can find that $\mathrm{SO}_{4}^{2-} / \mathrm{TiO}_{2}-\mathrm{La}_{2} \mathrm{O}_{3}$ was highly active, leading to yields of ten ketals and acetals up to $95.8 \%$ and no less than $41.4 \%$ after $1.0 \mathrm{~h}$. Moreover, the reaction temperature was controlled at the reflux temperature and the amount of $\mathrm{SO}_{4}^{2-} / \mathrm{TiO}_{2}-\mathrm{La}_{2} \mathrm{O}_{3}$ was much lower than that of other catalyst used in these reactions (Wang et al., 1992a; Zhang et al., 1995). All these helped to solve the technical problems of industrial processes.

When the temperature rose, we observed the solution of reagents became dark in color because

\begin{tabular}{|c|c|c|c|c|c|c|}
\hline Product & $\begin{array}{c}\text { Aldehyde/ketone } \\
\mathbf{1}\end{array}$ & $\begin{array}{l}\text { Glycol } \\
\mathbf{2}\end{array}$ & $\begin{array}{l}\text { Range of boiling } \\
\text { point }\left({ }^{\circ} \mathrm{C}\right)\end{array}$ & $\begin{array}{l}\text { Refractive } \\
\text { index }\end{array}$ & Yield (\%) & $\operatorname{IR}\left(\mathrm{cm}^{-1}\right)$ \\
\hline $3 \mathbf{a}$ & $\stackrel{\mathrm{O}}{\|} \stackrel{\mathrm{O}}{\mathrm{CH}_{3}-\mathrm{C}}-\mathrm{CH}_{2}-\stackrel{\mathrm{C}}{\|}-\mathrm{OCH}_{2} \mathrm{CH}_{3}$ & $\mathrm{HO}\left(\mathrm{CH}_{2}\right)_{2} \mathrm{OH}$ & $\begin{array}{l}126 \sim 128 \\
(6.7 \mathrm{kPa})\end{array}$ & 1.4325 & 84.7 & $\begin{array}{l}1738,1375, \\
1244,1188, \\
1047\end{array}$ \\
\hline $3 \mathbf{b}$ & $\stackrel{\mathrm{O}}{\mathrm{CH}_{3}-\stackrel{\mathrm{C}}{\mathrm{C}}-\mathrm{CH}_{2}-\stackrel{\mathrm{O}}{\mathrm{C}}-\mathrm{OCH}_{2} \mathrm{CH}_{3}}$ & $\mathrm{CH}_{3} \mathrm{CH}(\mathrm{OH}) \mathrm{CH}_{2} \mathrm{OH}$ & $\begin{array}{l}150 \sim 154 \\
(6.7 \mathrm{kPa})\end{array}$ & 1.4275 & 88.6 & $\begin{array}{l}1740,1377, \\
1244,1188, \\
1043\end{array}$ \\
\hline $3 c$ & & $\mathrm{HO}\left(\mathrm{CH}_{2}\right)_{2} \mathrm{OH}$ & $174 \sim 180$ & 1.4580 & 84.3 & $\begin{array}{l}2937,2863, \\
1163,1104\end{array}$ \\
\hline 3d & & $\mathrm{CH}_{3} \mathrm{CH}(\mathrm{OH}) \mathrm{CH}_{2} \mathrm{OH}$ & $172 \sim 176$ & 1.4493 & 84.6 & $\begin{array}{l}2937,2864, \\
1163,1103\end{array}$ \\
\hline $3 e$ & $\mathrm{CH}_{3} \mathrm{CH}_{2} \mathrm{COCH}_{3}$ & $\mathrm{HO}\left(\mathrm{CH}_{2}\right)_{2} \mathrm{OH}$ & $116 \sim 119$ & 1.4105 & 41.4 & $\begin{array}{l}1254,1215, \\
1194,1130\end{array}$ \\
\hline $3 f$ & $\mathrm{CH}_{3} \mathrm{CH}_{2} \mathrm{COCH}_{3}$ & $\mathrm{CH}_{3} \mathrm{CH}(\mathrm{OH}) \mathrm{CH}_{2} \mathrm{OH}$ & $126 \sim 130$ & 1.4102 & 64.6 & $\begin{array}{l}1250,1218 \\
1194,1157\end{array}$ \\
\hline $3 g$ & $\mathrm{CH}_{3} \mathrm{CH}_{2} \mathrm{CH}_{2} \mathrm{CHO}$ & $\mathrm{HO}\left(\mathrm{CH}_{2}\right)_{2} \mathrm{OH}$ & $130 \sim 134$ & 1.4190 & 95.3 & $\begin{array}{l}1146,1123, \\
1023,946\end{array}$ \\
\hline $3 \mathrm{~h}$ & $\mathrm{CH}_{3} \mathrm{CH}_{2} \mathrm{CH}_{2} \mathrm{CHO}$ & $\mathrm{CH}_{3} \mathrm{CH}(\mathrm{OH}) \mathrm{CH}_{2} \mathrm{OH}$ & $139 \sim 144$ & 1.4150 & 95.8 & $\begin{array}{l}1150,1123, \\
1024,970\end{array}$ \\
\hline $3 \mathbf{i}$ & $\mathrm{C}_{6} \mathrm{H}_{5} \mathrm{CHO}$ & $\mathrm{HO}\left(\mathrm{CH}_{2}\right)_{2} \mathrm{OH}$ & $226 \sim 230$ & 1.5264 & 80.0 & $\begin{array}{l}1096,1071, \\
1028,947\end{array}$ \\
\hline $3 \mathbf{j}$ & $\mathrm{C}_{6} \mathrm{H}_{5} \mathrm{CHO}$ & $\mathrm{CH}_{3} \mathrm{CH}(\mathrm{OH}) \mathrm{CH}_{2} \mathrm{OH}$ & $218 \sim 222$ & 1.5094 & 80.8 & $\begin{array}{l}1097,1067, \\
1011,976\end{array}$ \\
\hline
\end{tabular}

Table 1 Comparison of catalytic activities of different catalysts

\begin{tabular}{lcccc}
\hline \multicolumn{1}{c}{ Catalyst } & Molar ratio of alcohol to acid & Reaction time $(\mathrm{min})$ & The highest reaction temperature $\left({ }^{\circ} \mathrm{C}\right)$ & Yield $(\%)$ \\
\hline $\mathrm{SO}_{4}^{2-} / \mathrm{TiO}_{2}-\mathrm{La}_{2} \mathrm{O}_{3}$ & $1.3: 1$ & 60 & 114 & 94.7 \\
$\mathrm{H}_{2} \mathrm{SO}_{4}$ & $1.0: 1$ & 120 & 158 & 72.1 \\
$\mathrm{H}_{3} \mathrm{PW}_{12} \mathrm{O}_{40}$ & $1.0: 1$ & 113 & 140 & 62.5 \\
\hline
\end{tabular}

Table 2 Synthetic results of 10 classes of acetals and ketals 
temperature above the optimum condition would decrease the activity of catalyst. More reaction time was needed to keep the yield but the activity began to decrease after two hours. Comparing the 2 alcoholic reactants, the special steric hindrance and the density of electron atmosphere on oxygen atoms exerted opposite effects on yield. The former kept oxygen atoms from approaching carbonium ions and the $\mathrm{C}-\mathrm{O}$ binding was difficult to form. But the latter decreased the density of electron atmosphere on oxygen atoms bonded with carbonium ions so as to alleviate the rejection of the electron atmosphere of two oxygen atoms. To reactions $\mathbf{3} \mathbf{a}$ and $\mathbf{3} \mathbf{j}$, the special steric hindrance disadvantageous effect and took the leading role. For the rest, the density of electron atmosphere on oxygen atom predominated.

\section{CONCLUSION}

The following conclusions can be drawn from this study: (1) The optimum synthetic conditions of $\mathrm{SO}_{4}^{2-} / \mathrm{TiO}_{2}-\mathrm{La}_{2} \mathrm{O}_{3}$ are: mole ratio of $n\left(\mathrm{La}^{3+}\right): n\left(\mathrm{Ti}^{4+}\right)$ is $1: 34$, the soaked consistency of $\mathrm{H}_{2} \mathrm{SO}_{4}$ is $0.8 \mathrm{~mol} / \mathrm{L}$, impregnation time of $\mathrm{H}_{2} \mathrm{SO}_{4}$ is $24 \mathrm{~h}$, the calcination temperature is $480^{\circ} \mathrm{C}$, the calcining time is $3 \mathrm{~h}$. (2) The molar ratio of aldehyde/ketone to glycol is $1: 1.5$, the mass ratio of the catalyst used in the reactants is $0.5 \%$, and the reaction time is $1.0 \mathrm{~h}$, the yields of ketals and acetals can reach $41.4 \%$ 95.8\%. (3) The esterification of $n$-butanoic acid and $n$-butyl alcohol as probing reaction showed efficiently highly catalytic activity of $\mathrm{SO}_{4}^{2-} / \mathrm{TiO}_{2}-\mathrm{La}_{2} \mathrm{O}_{3}$ at its optimum conditions as catalyst. At the same time, it also shows much higher catalytic activity than other solid acid catalysts, such as $\mathrm{H}_{2} \mathrm{SO}_{4}, \mathrm{H}_{3} \mathrm{PW}_{12} \mathrm{O}_{40}$, and so on. Valuable products, ten important ketals and acetals have been obtained at high yield.

\section{References}

Dhrubojyoti, D., Laskar, D.P., Jagir, S.S., 1999. Cadmium iodide catalyzed and efficient synthesis of acetals under microwave irradiations. Chemistry Letters, 332(8): 1283-1284.

Gao, Z., Chen, J.M., Tang, Y., 1992. Studies on the formation of $\mathrm{ZrO}_{2} / \mathrm{SO}_{4}^{2-}$ superacid system. Chem. J. Chinese Universities, 13(12):1498-1502 (in Chinese).

Gao, Z., Chen, J.M., Tang, Y., 1994. Linear alkane reactions on $\mathrm{SO}_{4}^{2-} / \mathrm{ZrO}_{2}$ solid superacid catalysts. Acta Chimica
Sinica., 52(1):36-41 (in Chinese).

Gao, G.Z., Yu, S.T., Yang, J.Z., 1996. Preparation of $\mathrm{SO}_{4}^{2-} / \mathrm{TiO}_{2}-\mathrm{Al}_{2} \mathrm{O}_{3}-\mathrm{SnO}_{2}$ and its catalytic properties for the synthesis of dioctyl adipate. Chinese Journal of $\mathrm{Ca}$ talysis, 17(1):83-86 (in Chinese).

Hess, A., Kemnitz, E., 1997. Surface acidity and catalytic behavior of modified zirconium and titanium dioxides. Appl. Catal. A: Gen., 149(2):373-378. [doi:10.1016/ S0926-860X(96)00247-5]

Kirbaslar, S.I., Terzjoglu, H.Z., Dramur, U., 2001. Catalytic esterification of methyl alcohol with acetic acid. Chinese J. Chem. Eng., 9(1):90-96.

Li, Y.Q., Cheng, L.H., 2001. A rapid and convenient synthesis of acylals from aldehydes and acetic anhydrides catalyzed by $\mathrm{SnCl}_{4} / \mathrm{SiO}_{2}$. Chinese Chemistry Letters, 12(7):565-568.

Li, T.S., Li, S.H., Li, J.T., Li, H.Z., Wu, X.X., 1996. Efficient and convenient procedures for the formation and cleavage of steroid acetals catalyzed by montmorillonite K10. Chinese Chemistry Letters, 7(11):975-978.

Loader, C.E., Anderson, H.J., 1978. Pyrrole chemistry part XX: synthesis of pyrrole acetals. Synthesis, 1978(4):295-297. [doi:10.1055/s-1978-24728]

Lu, Z.K., Zu, W.R., 2002. Synthesis of isopropyl salicylicate with solid ferric suiphate as a catalyst. Chin. J. Org. Chem., 22(6):450-452 (in Chinese).

Ma, D.F., Li, Y., 2002. Synthesis and application of complex solid superacid $\mathrm{WO}_{3}-\mathrm{TiO}_{2}-\mathrm{SO}_{4}^{2-}$. Fine Chemicals, 19(1): 36-38 (in Chinese).

Pan, X.M., Xie, Y.C., 2001. Monolayer dispersion threshold determined by XRD quantitative phase analysis. University Chemistry, 16(3):36-39 (in Chinese).

Wang, C.D., Niu, Y.Q., Lu, J., 1992a. Acetalation and ketal formation catalyzed by stannous oxide. Journal of Yangzhou Institute of Technology, 4(1):40-43 (in Chinese).

Wang, C.D., Yang, X.H., Qian, W.Y., 1992b. Synthesis of acetals and ketals with solid superacid catalyst $\mathrm{TiO}_{2} / \mathrm{SO}_{4}^{2-}$. Fine Chemicals, 9(3):4-7 (in Chinese).

Yang, S.J., Yu, X.Q., Liang, Y.G., Sun, J.T., 2003. Synthesis of ethyl acetoacetate ethylene ketal catalyzed by using $\mathrm{TiSiW}_{12} \mathrm{O}_{40} / \mathrm{TiO}_{2}$. Journal of Molecular Catalysis, 17(1):61-64 (in Chinese).

Yang, S.J., Du, X.X., He, L., Sun, J.T., 2005a. Synthesis of acetals and ketals catalyzed by tungstosilicic acid supported on active carbon. Journal of Zhejiang University SCIENCE, 6B(5):373-377. [doi:10.1631/jzus.2005. B0373]

Yang, S.J., Liang, Y.G., Yu, X.Q., Sun, J.T., 2005b. Preparation of $\mathrm{SO}_{4}^{2-} / \mathrm{TiO}_{2}-\mathrm{MoO}_{3}$ solid super acid and its catalytic activities in acetalation and ketalation. Chinese Journal of Chemical Engineering, 13(1):51-55.

Yin, X.L., Han, H.M., Guo, L.Y., Xia, K., Huang, J.H., 1994. Study on preparation and properties of $\mathrm{SO}_{4}^{2-} /\left(\mathrm{ZrO}_{2}-\right.$ $\mathrm{TiO}_{2}-\mathrm{SnO}_{2}$ ) catalysts. Petrochemical Technology, 23(1): 22-26 (in Chinese).

Zhang, J.F., Shao, H.Y., Yang, J.Y., 1993. The application of heteropolyacid catalyst in esterification. Speciality Petrochemicals, (1):51-53 (in Chinese).

Zhang, J.F., Chen, T., Zhang, D.X., Shen, L., 1995. Catalytic synthesis of acetals and ketals with heteropoly-acid. Flavour Fragrance Cosmetics, (4):25-27 (in Chinese). 